Discussion Paper No. 760

\title{
NOMINAL WAGE ADJUSTMENT, DEMAND SHORTAGE AND ECONOMIC POLICY
}

\author{
Yoshiyasu Ono \\ Junichiro Ishida
}

November 2009

The Institute of Social and Economic Research

Osaka University

6-1 Mihogaoka, Ibaraki, Osaka 567-0047, Japan 


\title{
Nominal Wage Adjustment, Demand Shortage and Economic Policy*
}

\author{
Yoshiyasu $\mathrm{Ono}^{\dagger}$ and Junichiro Ishida ${ }^{\ddagger}$
}

November 2009

\begin{abstract}
We formulate nominal wage adjustment by incorporating various concepts of fairness. By applying it into a continuous-time money-in-utility model we examine macroeconomic dynamics with and without a liquidity trap and obtain the condition for persistent unemployment, and that for temporary unemployment, to occur. These conditions turn out to be critical, since policy implications significantly differ between the two cases. A monetary expansion raises private consumption under temporary unemployment but does not under persistent unemployment. A fiscal expansion may or may not increase short-run private consumption but crowds out long-run consumption under temporary unemployment. Under persistent unemployment, however, it always increases private consumption.
\end{abstract}

Keywords: Wage adjustment, Fairness, Phillips curve, Demand shortage, Persistent stagnation

JEL Classification Numbers: E52, E31.

\footnotetext{
*The authors would like to thank S. Ikeda, T. Matsumura, R. Murota, T. Ogawa and S. Tanaka for their valuable comments. They acknowledge the financial support from the GCOE (Global Center of Excellence) program, Ministry of Education, Culture, Sports, Science and Technology; and Grantsin-Aid for Scientific Research, JSPS.

$\dagger$ Institute of Social and Economic Research, Osaka University, 6-1 Mihogaoka, Ibaraki, Osaka 567-0047, Japan. E-mail:ono@iser.osaka-u.ac.jp, Tel:+81-6-6879-8578, Fax:+81-6-6878-2766.

${ }^{\ddagger}$ Institute of Social and Economic Research, Osaka University
} 


\section{Introduction}

We extend the fair wage model of Akerlof and Yellen (1990) to a continuous-time dynamic model of a monetary economy as portrayed by Keynes (1936, chap.17). Various concepts of wage fairness are incorporated to this framework to provide a microeconomic foundation for sluggish nominal wage adjustment. In this setup, we find that persistent unemployment may arise in the presence of a liquidity trap and obtain the condition for persistent unemployment, and that for temporary unemployment, to occur. These conditions turn out to be critical, since effects of fiscal and monetary policies on aggregate demand are shown to be quite different between the two cases.

When analyzing unemployment, whether temporary or permanent, we must consider sluggish price/wage adjustment, viz. the Phillips curve,${ }^{1}$ since any possibility of demand-supply imbalance would intrinsically be avoided without it. Ono (1994, 2001) presents a dynamic optimization model of a monetary economy with sluggish nominal wage adjustment and shows that unemployment persists in the steady state if there is a positive lower bound of the marginal utility of liquidity. This setting, which captures Keynes's notion of a monetary economy, ${ }^{2}$ has recently been used in various analyses of persistent stagnation. ${ }^{3}$ All of these previous studies, however, simply take the original Phillips curve as given, leaving the nominal wage adjustment process as a complete black box.

Since the original Phillips curve sorely lacks any microeconomic foundation for the

\footnotetext{
${ }^{1}$ As an alternative to the sticky-price approach, Mankiw and Reis (2002) propose a stickyinformation model where information diffuses slowly through the population.

${ }^{2}$ Keynes (1936, chap.17) defines a non-monetary economy as an economy where there is no asset such that its liquidity premium remains strictly positive.

${ }^{3}$ For example, Matsuzaki (2003) finds the effect of a consumption tax on effective demand in the presence of poor and rich people. Hashimoto (2004) examines the intergenerational redistribution effects of the public pensions system in an overlapping generations framework with the present type of stagnation. Ono (2006) extends the model into a two-country framework and analyzes the spillover effects of fiscal spending. Johdo (2006) considers the relationship between R\&D subsidies and unemployment. Rodriguez-Arana (2007) examines the dynamic path with public deficit in the present stagnation case and compares it with that in the neoclassical case. Johdo and Hashimoto (2008) introduce FDI into a two-country model with the present stagnation mechanism and analyze the effect of the corporation tax on employment in each country. Murota and Ono (2008) find that a preference for money holding as status is insaiable and thus generates persistent stagnation of the present type.
} 
nominal wage adjustment process, several attempts have been made to augment it in this direction: among most notable are the New Classical Phillips curve, the New Keynesian Phillips curve and the hybrid of the two. ${ }^{4}$ Models along this line include e.g. Yun (1996), Woodford (2003), Gali (2008), Dotsey et al. (1999), Golosov and Lucas (2007) and Gertler and Leahy (2008). The first three assume Calvo's staggered pricing while the others adopt the menu cost approach. They examine firm and household reactions to a policy or parameter shock that occurs in the middle of the initial period. Since they assume that agents cannot revise prices or wages in the middle of each period, demand-supply imbalances arise in the initial period but disappear in subsequent periods. Krugman (1998) also analyzes Japan's stagnation using a two-period model in which prices are rigid only in the initial period and any demand shortages disappear in the second period.

What is common among these studies is that they preclude the possibility of demand shortages in the steady state, almost by construction. ${ }^{5}$ The logic of unemployment in this existing literature is indispensably based on the assumption that there is a period within which prices and wages cannot be revised. According to this logic, unemployment is necessarily a temporary phenomenon which occurs only in the adjustment process, as any demand shortages would eventually dissipate once people's expectations are corrected and prices are completely adjusted. Therefore, although certainly insightful in understanding short-run fluctuations, these existing settings face serious difficulties in explaining long and persistent recessions because, for them to occur, it must be either (i) that people continuously make false expectations about prices or (ii) that the price/wage adjustment process is extremely slow. Neither appears to be a likely cause for persistent recessions, such as the Great Depression of the 1930s, Japan's lost decade of the 1990s, and many other prolonged economic downturns which we observe every now and then. ${ }^{6}$ In many of those instances, the recessions persisted

\footnotetext{
${ }^{4}$ See Woodford (2003) for properties of these Phillips curves.

${ }^{5}$ In these settings, the existence of demand shortages implies that the deflation rate cumulatively expands. If this were to continue, prices would reach zero within a finite time and the feasibility condition would eventually be violated.

${ }^{6}$ See Kehoe and Prescott (2007) for many "great depressions" of the twentieth century.
} 
for more than a decade, which should be more than enough for people to adjust expectations correctly. It is also implausible to think that the price/wage adjustment process is so slow that even after all these years, prices and wages cannot be adjusted to the equilibrium levels to clear the markets.

It is our view that, to account for long and persistent deviations from full employment, we need an alternative framework where the presence of unemployment does not hinge on unexpected events or policies. To illuminate this point, we construct a model of perfect foresight with no unexpected shocks where everyone precisely understands the current state of the economy. ${ }^{7}$ Moreover, we adopt a continuous-time setting which inherently has no border of periods: at any point in time, firms are free to set any prices and wages, so that there is no "adjustment" in this particular sense. We instead consider a nominal wage adjustment process which rests on workers' inherent concerns for fairness. This adjustment mechanism is introduced to a dynamic general equilibrium setting to provide our own version of the Phillips curve with its microeconomic foundation: in the current variation, the inflation rate is governed by the liquidity premium, the subjective discount rate and the unemployment rate; in particular, around the steady state, the inflation rate depends only on the unemployment rate, as in the original Phillips curve.

Within this framework, we show that unemployment due to demand shortages may persist in the presence of a liquidity trap, thereby pointing to a specific route through which persistent recessions arise as an equilibrium phenomenon. Aggregate demand falls short of its full-employment level because people hold onto liquid assets, viz. money, in the shadow of a recession, which in turn stagnates aggregate demand. The driving force behind persistent unemployment is hence our perpetual and insatiable carving for money, whereas the role of nominal wage rigidity is fundamentally different from the previous models: in fact, while the insatiable demand for money is the direct cause of persistent unemployment, nominal wage rigidity works more as a buffer,

\footnotetext{
${ }^{7}$ Obviously, this is not to say that expectations play no role in aggregate fluctuations; they most certainly do. What we argue here is rather that unemployment could persist even under perfect foresight where there are no surprises.
} 
preventing the economy from falling into a catastrophic disaster. Given this construction, we identify conditions that delineate persistent and temporary unemployment and show that policy implications differ substantially between the two cases: that is, what works under temporary stagnation may not work under persistent stagnation. In light of these findings, we argue that different sets of remedies may be needed to restore full employment once the economy gets stuck in the state of persistent stagnation.

Despite all the advancements made over the past years, it still remains to be a daunting task to fully understand the underlying mechanism of prolonged recessions which we face from time to time. The main aim of this paper is to contribute to this long-standing issue, especially focusing on why recessions, once started, often persist for so long. On a grand scale, this paper shares a lot with the New Keynesian paradigm in its motivation and fundamental approach: we turn to Keynes as the source of insight on malfunctioning economies. ${ }^{8}$ The problem is that his book "The General Theory of Employment, Interest, and Money" is painfully convoluted, and critical insights are scattered throughout the book in a rather unstructured way. Still, many attempts have been made to pick up pieces of his insight and reduce them down to their essence. An emerging consensus seems to be that the crux of Keynesianism lies in various sorts of market imperfection, especially nominal rigidity, whose effects are amplified through the effect of aggregate demand.

We have no intention of arguing with this general consensus in this paper, as there is little doubt that nominal rigidity constitutes a critical component of Keynes's theory. It is our stance, however, that nominal rigidity alone does not exhaust all of Keynes's insight. We argue that there is an overlooked aspect of his theory that is of independent importance, i.e., the role of insatiable liquidity preferences. This paper is an attempt to recast and revitalize this insight in a modern macroeconomic framework to derive its dynamic policy implications. Although this insight has somehow escaped economists'

\footnotetext{
${ }^{8}$ Several prominent economists make this point rather emphatically. Greg Mankiw notes "If you were going to turn to only one economist to understand the problems facing the economy, there is little doubt that the economist would be John Maynard Keynes.... His insights go a long way toward explaining the challenges we now confront (New York Times, November 28). "The Keynesians basically got it right," says George Akerlof (2007).
} 
attention, especially in a rigorous context, we believe that the current framework sheds light on a different side of Keynesianism and provides a useful prescription of prolonged recessions.

\section{The wage dynamics}

Before we set up a dynamic optimization problem, we first illustrate the wage adjustment process which describes how nominal wages are determined in this economy. As stated, the driving force behind this whole process is workers' inherent concerns for fairness. Having derived the equilibrium wage dynamics we then incorporate it into a dynamic general equilibrium framework to close the model in the next section.

\subsection{The setup}

There are continua of identical workers and firms, both with unit measure. At any instance, each worker is either employed or unemployed. Since firms are all identical, unemployed workers are randomly assigned to firms whenever vacancies exist: as a consequence, each firm hires workers of equal size in any equilibrium. Let $x(t)$ denote the number of workers newly hired at time $t$ which is constant across firms. Moreover, define $X(t)$ as the aggregate rate of employment $X(t) \in[0,1]$, where $X(t)=1$ means that the economy is in the state of full employment.

Although employed workers can in principal quit and leave their respective firms at will, workers must incur some flow cost while they are unemployed. ${ }^{9}$ We assume that the cost of unemployment is prohibitively large, so that workers would not choose to voluntarily leave their firms when there is a positive probability of being unemployed. This means that their mobility is heavily influenced by the aggregate rate of employment: workers are perfectly mobile when $X(t)=1$, but they are virtually held up by their respective firms when $X(t)<1$. These assumptions are made for clarity and tractability rather than for realism. ${ }^{10}$

\footnotetext{
${ }^{9}$ The cost of unemployment is meant to capture physical costs of job search as well as more psychological costs of anxiety or social stigma inherently attached to unemployment.

${ }^{10}$ All we need is the fact that workers' mobility is more limited when there are more unemployed
} 
In this model, since both firms and workers are identical and there is no information asymmetry, job separations occur only for exogenous reasons (no voluntary job separations on any equilibrium path) as long as unemployment exists. We assume that each employed worker randomly separates from the current firm at Poisson rate $\alpha$. The aggregate rate of employment is then obtained as

$$
X(t)=\int_{-\infty}^{t} x(s) e^{\alpha(s-t)} d s
$$

The time differentiation of (1) yields

$$
\dot{X}(t)=-\alpha X(t)+x(t)
$$

Note that when $X(t)=1$ and $x(t)=\alpha$, full employment continues. Throughout the analysis, we restrict attention to the case where $\alpha$ is relatively small so that $\rho>\alpha .{ }^{11}$

\subsection{Wage setting}

At each instance $t$, each firm $i \in[0,1]$ offers a (take-it-or-leave-it) wage $w(i, t)>0$ that applies equally for all of its employed workers. Define

$$
W(t) \equiv \frac{\int_{0}^{1} \sigma(i) w(i, t) d i}{\int_{0}^{1} \sigma(i) d i},
$$

as the economy-wide average wage, where $\sigma(i)$ is the weight given to firm $i$. When unemployed, each worker receives unemployment benefits $b(t)$, which we later normalize to zero for all $t .{ }^{12}$

We suppose that workers in this economy have a strong preference for being treated fairly, and their motivation and productivity depend heavily on this fairness concern. To be more precise, let $\omega(t)$ denote the nominal wage level that is perceived as fair by employed workers at time $t$ : in what follows, we simply refer to $\omega(t)$ as the fair

workers waiting for job offers and the expected duration of unemployment is longer. Our assumptions should thus be viewed as a way to capture this aspect of reality in an analytically tractable manner.

${ }^{11}$ If the job-separation rate $\alpha$ is regarded as the rate of death as a worker, it is naturally less than the subjective discount rate $\rho$.

${ }^{12}$ The presence of unemployment benefits plays no role in the analysis, but it helps clarifying the definition of the fair wage which we discuss next. 
wage. When $w(i, t) \geq \omega(t)$, each worker perceives that the current wage is "fair" and produces $\theta$ (per unit of time); when $\omega(t)>w(i, t)$, each worker perceives that the current wage is "unfair" and produces nothing by withholding work effort. Note that this specification is a variant of the fair wage-effort hypothesis, put forth by Akerlof and Yellen (1990), which posits that a worker's productivity goes down when the wage level dips below what is perceived as fair.

\subsection{The fair wage}

Under this setup, what becomes critical is how workers develop the perception of fairness. At a general level, since fairness is inherently a distributional concern, it should be subject to various kinds of social comparisons. While it is undoubtedly true, what social comparisons can imply is potentially very broad and somewhat vague. More restrictions are thus needed to pin down a tightly specified process of fairness formation. To do this, we build on the following four popular views in social psychology and behavioral economics:

1. The entitlement effect: Once a high wage is offered, people develop a sense of entitlement which persists over time (Falk et al., 2006).

2. The anchoring effect: One's perceptions, preferences and valuations are initially malleable but, once imprinted, become fairly persistent over time (Ariely et al., 2003). 3. Opinion-based transmission of perceptions: Others' perception of fairness influences one's own perception of fairness (Folger and Kass, 2000; Umphress et al., 2003).

4. The belief in the just world: People are motivated to help others who have been treated unfairly, to make the world fair and just again (Lerner, 1980).

For illustrative purposes, we momentarily consider a discrete-time version of the model where each firm hires new workers and revises its wage contract at interval of $\Delta t$, i.e., at time $t \in T \equiv\left\{\ldots, t_{0}-\Delta t, t_{0}, t_{0}+\Delta t, \ldots\right\}$. We posit that the fair wage in this economy is computed through the following two-stage process. ${ }^{13}$

\footnotetext{
${ }^{13}$ Note that the current specification is a way, possibly among some others, to capture the four aforementioned views in a unified form.
} 
First Stage: At any $t \in T$, workers can be classified into either one of the three classes: remaining workers who continue to be employed, incoming workers who are newly hired, and unemployed. The fair wage is computed mainly from the viewpoint of the remaining workers. First, those remaining workers have in mind a (common) wage level, denoted by $\nu(t)$, that they are rightfully entitled to. Taking this as the basis, they also take into account the well-beings of unemployed workers (the justworld hypothesis). ${ }^{14}$ The fair wage at time $t_{0}$ is obtained as the average, weighted by the number of each class of workers, of these concerns:

$$
\omega\left(t_{0}\right)=\frac{\nu\left(t_{0}-\Delta t\right) X\left(t_{0}-\Delta t\right)(1-\alpha \Delta t)+b\left(t_{0}\right)\left(1-X\left(t_{0}\right)\right)}{1-x\left(t_{0}\right) \Delta t},
$$

where the denominator equals the total number of the remaining workers and the unemployed, as is clear from (2). At this point, the incoming workers, with no prior work experiences, basically have no idea of what is supposed to be fair and simply accept and internalize their predecessors' view (opinion-based transmission of perceptions).

Second Stage: Immediately after time $t_{0}$, the incoming workers are quickly assimilated into the remaining workers. With new wage contracts in effect, all the employed workers, both remaining and incoming, then readjust their perception $\nu(t)$. Two factors enter into this readjustment process: on one hand, their perception is influenced to some extent by the current average wage (the entitlement effect); on the other hand, it is also influenced by their past perceptions (the anchoring effect). Given this, their adjusted perception is obtained as

$$
\delta W\left(t_{0}\right)+(1-\delta) \omega\left(t_{0}\right)=\nu\left(t_{0}\right) X\left(t_{0}\right)+b\left(t_{0}\right)\left(1-X\left(t_{0}\right)\right),
$$

where $\delta \in[0,1]$ measures the relative salience of the entitlement effect.

The fair wage is shaped by going through this two-stage process repeatedly over time. Since we normalize $b(t)=0$ for all $t$, combining (4) and (5) yields

$$
\omega\left(t_{0}\right)=\frac{\left(\delta W\left(t_{0}-\Delta t\right)+(1-\delta) \omega\left(t_{0}-\Delta t\right)\right)(1-\alpha \Delta t)}{1-x\left(t_{0}\right) \Delta t}
$$

\footnotetext{
${ }^{14}$ Since workers are all homogeneous and unemployed workers are simply unlucky to be in that state, workers are to some extent willing to take a wage cut, by lowering their fair wage, in order to help them out.
} 
which characterizes how the fair wage in this economy evolves over time.

\subsection{The equilibrium wage adjustment}

We assume perfect market competition among firms, each of which acts as a pricetaker in the goods market. Let $P(t)$ denote the aggregate price of the good. At time $t \in T$, each firm unilaterally offers a wage $w(i, t)$ to its employed workers, taking the sequence of all the aggregate variables $\{W(s), P(s), x(s)\}_{s=-\infty}^{t}$ as given. This means that each firm also takes the fair wage $\omega(t)$ as given when it offers its own wage. Since the cost of unemployment is prohibitively large, there is a fine line between $X(t)<1$ and $X(t)=1$, and the nature of wage setting differs completely depending on whether the economy achieves full employment or not.

We first characterize the equilibrium wage adjustment process in the presence of unemployment, i.e., $X(t)<1$. In this case, workers are completely immobile and have no choice but to accept wages offered by their respective firms. While bargaining power is entirely in the hands of firms, workers can withhold work effort whenever they feel they are slighted. With this fairness concern as a credible threat, firms can lower the wages only down to the fair wage level. The following is a formal representation of this fact.

Proposition 1 When $X(t)<1, w(i, t)=\omega(t)$ for all $i \in[0,1]$.

Proof: First, if firm $i$ chooses to hire a worker, it must be that $w(i, t) \geq \omega(t)$. To see this, note that if $\omega(t)>w(i, t)>0$, the worker who never quits produces nothing and consequently yields a negative profit. It is then strictly better not to hire the worker in the first place. Second, it is also straightforward to see that firms have no incentive ex post to offer a wage that is strictly larger than the fair wage, because that would only decrease their profits. It follows from these observations that firms simply offer the fair wage at every instance when $X(t)<1$.

Q.E.D. 
The proposition means that the evolution of the fair wage totally dictates the equilibrium wage dynamics in the presence of unemployment. First, since $w(i, t)=\omega(t)$ for all $i$, we have $W(t)=\omega(t)$ for any given weight $\{\sigma(i)\}_{i=0}^{1}$. It then follows from (3) and (6) that

$$
W\left(t_{0}\right)=W\left(t_{0}-\Delta t\right)(1-\alpha \Delta t)+W\left(t_{0}\right) x\left(t_{0}\right) \Delta t .
$$

The equilibrium wage dynamics is governed by this adjustment process. Letting $\Delta t \rightarrow$ 0 , we obtain

$$
\frac{\dot{W}\left(t_{0}\right)}{W\left(t_{0}\right)}=\lim _{\Delta t \rightarrow 0} \frac{W\left(t_{0}\right)-W\left(t_{0}-\Delta t\right)}{W\left(t_{0}-\Delta t\right) \Delta t}=\lim _{\Delta t \rightarrow 0} \frac{x\left(t_{0}\right)-\alpha}{1-x\left(t_{0}\right) \Delta t}=x\left(t_{0}\right)-\alpha .
$$

The nature of wage setting drastically changes once the economy achieves full employment, i.e., $X(t)=1$. Workers are now fully mobile in search of the best wage offer available to them without facing any risk of being unemployed. Consequently, the market price $P(t)$ dictates the equilibrium dynamics, and the fair wage may play no role. Since workers are mobile, competition among firms for workers drives up the wage offers up to $\theta P(t)$. We can thus establish the following result.

Proposition 2 When $X(t)=1, w(i, t)=\theta P(t)$ for all $i \in[0,1]$.

Proof: First, it is evident that no firm offers $w(i, t)>\theta P(t)$ because it yields a strictly negative profit. Suppose that $\theta P(t)>w_{\max } \equiv \max _{i} w(i, t)$. Then, a firm can offer a wage that is slightly larger than $w_{\max }$ and attract all workers away from other firms. This means that the only equilibrium with perfect worker mobility is to offer $w(i, t)=\theta P(t)$.

Q.E.D.

In either case, whether there is unemployment or not, $w(i, t)=W(t)$ for all $i \in[0,1]$. Perfect market competition then forces all firms to break even and earn zero profit in equilibrium. The following zero-profit condition thus always holds:

$$
\theta P(t)=W(t) .
$$




\section{General equilibrium}

In the previous section, we have derived the nominal wage adjustment process which stems from workers' fairness concerns. We now incorporate this process into a dynamic general equilibrium framework which admits the possibility of equilibrium unemployment.

The problem we consider is a standard dynamic money-in-utility optimization problem (in what follows, we abbreviate time notation to simplify exposition). The lifetime utility of a representative household is given by

$$
U=\int_{0}^{\infty}[u(c)+v(m)] \exp (-\rho t) d t
$$

where $\rho$ is the subjective discount rate, $c$ is real consumption and $m \equiv M / P$ is real money balances. The representative household maximizes $U$ subject to the flow budget equation:

$$
\dot{m}=w X-\pi m-c-z,
$$

where $\pi$ is the inflation rate, $z$ is the lump-sum tax-cum-subsidy and $w$ is the real wage $W / P$. Since all firms earn zero profit under perfect market competition, the only storable asset in this economy is the real balances $m .{ }^{15}$ The first-order optimal condition of this problem is

$$
\eta \frac{\dot{c}}{c}+\rho+\pi=\frac{v^{\prime}(m)}{u^{\prime}(c)} \text { where } \eta \equiv-\frac{u^{\prime \prime}(c) c}{u^{\prime}(c)}
$$

and the transversality condition is

$$
\lim _{t \rightarrow \infty} \lambda(t) m(t) \exp (-\rho t)=0
$$

where $\lambda(t)$ is the costate variable of $m$ which equals $u^{\prime}(c)$.

The government's budget constraint is

$$
z+\mu m=g,
$$

\footnotetext{
${ }^{15}$ Even if there are government bonds, the present analysis is unchanged since the Ricardian equivalence holds.
} 
where $g$ represents government purchases and $\mu$ is the monetary expansion rate:

$$
\frac{\dot{M}}{M}=\mu
$$

Given the definition of $m$, this can also be written as

$$
\frac{\dot{m}}{m}=\mu-\pi
$$

The general equilibrium properties of the model differ sharply, depending on whether there is unemployment or not. In the presence of unemployment, (8) and (9) give

$$
\pi=\frac{\dot{W}}{W}=x(t)-\alpha
$$

On any equilibrium path, all employed workers are motivated enough to exert effort and hence the total production is always $\theta X$, as discussed in the previous section. Therefore, under perfect commodity price adjustment, we must have

$$
c+g=\theta X
$$

From (2), (12) and the time derivative of (18),

$$
\frac{v^{\prime}(m)}{u^{\prime}(c)}-\pi-\rho=\eta\left(\frac{c+g}{c}\right)\left(\frac{x}{X}-\alpha\right)
$$

Combined with (17) and (18), (19) yields

$$
\frac{\dot{P}}{P}=\pi=\frac{c}{c+\theta \eta}\left(\frac{v^{\prime}(m)}{u^{\prime}(c)}-\rho+\frac{\alpha \eta \theta}{c}\left(\frac{c+g}{\theta}-1\right)\right),
$$

which is our version of the Phillips curve. Substituting (20) into (12) and (16) and rearranging the results produces

$$
\begin{aligned}
\frac{\dot{m}}{m} & =\mu-\frac{c}{c+\theta \eta}\left(\frac{v^{\prime}(m)}{u^{\prime}(c)}-\rho+\frac{\alpha \eta \theta}{c}\left(\frac{c+g}{\theta}-1\right)\right), \\
\frac{\dot{c}}{c} & =\frac{\theta}{c+\theta \eta}\left(\frac{v^{\prime}(m)}{u^{\prime}(c)}-\rho-\alpha\left(\frac{c+g}{\theta}-1\right)\right) .
\end{aligned}
$$

These two equations constitute an autonomous dynamic system with respect to $m$ and $c$ in the presence of unemployment. 
Remark: Under the current Phillips curve (20), the inflation rate is governed by the liquidity premium $v^{\prime}(m) / u^{\prime}(c)$, the subjective discount rate $\rho$ and the unemployment rate $1-(c+g) / \theta$. More importantly, substituting (12) into this, we obtain

$$
\pi=\frac{\dot{c}}{\theta}+\alpha\left(\frac{c+g}{\theta}-1\right)
$$

This indicates that as the economy approaches the steady state $(\dot{c} \rightarrow 0)$, the inflation rate depends solely on the unemployment rate. The current framework hence provides a microeconomic foundation for the relationship between the unemployment rate and the inflation rate, as the original Phillips curve posits.

If full employment is realized $(X=1)$, on the other hand, we have

$$
c=\theta-g
$$

From (12), (16) and (23), we obtain

$$
\frac{\dot{m}}{m}=\rho+\mu-\frac{v^{\prime}(m)}{u^{\prime}(\theta-g)},
$$

which is the same as the standard dynamics of the money-in-utility model (see e.g. Blanchard and Fischer, 1989). From the beginning, therefore, $P$ takes the level that satisfies

$$
\rho+\mu=\frac{v^{\prime}(M / P)}{u^{\prime}(\theta-g)}
$$

and thereafter rises at the same pace as $\mu$, so that $M / P$ remains at the constant level that satisfies (24). From (9), $\theta P=W$ and hence $W$ also rises at the rate of $\mu$. Thus, in this case the Phillips curve forms a vertical line as $\mu$ changes.

\section{Temporary Unemployment}

Using the dynamic equations obtained in the previous section we draw the phase diagram and analyze the properties of the present dynamics. This section first considers the case with no liquidity trap, where the marginal utility of liquidity has no positive 
lowerbound, i.e., $\lim _{m \rightarrow 0} v^{\prime}(m)=0$, so that the demand for liquidity would eventually dissipate. Under this condition, any equilibrium path reaches the full-employment steady state and unemployment occurs only during the adjustment process.

From (21), the boundary curve of $m$ dynamics and that of $c$ dynamics are given by

$$
\begin{aligned}
\dot{m} & =0: \quad v^{\prime}(m)=\left(\rho-\frac{\theta \eta \alpha}{c}\left(\frac{c+g}{\theta}-1\right)+\mu\left(1+\frac{\theta \eta}{c}\right)\right) u^{\prime}(c) . \\
\dot{c} & =0: \quad v^{\prime}(m)=\left(\rho+\alpha\left(\frac{c+g}{\theta}-1\right)\right) u^{\prime}(c) .
\end{aligned}
$$

The right-hand side of the $\dot{m}=0$ curve is obviously a decreasing function with respect to $c$ whereas the right-hand side of the $\dot{c}=0$ curve can be sloped either positively or negatively. If the aggregate demand $c+g$ is less than the full-employment supply $\theta$, and $\mu$ is non-negative, the right-hand side of the $\dot{m}=0$ curve is larger than that of the $\dot{c}=0$ curve. Thus, since $v^{\prime \prime}(m)<0$, the $\dot{m}=0$ curve is located on the left-hand side of the $\dot{c}=0$ curve. Figure 1 illustrates the two curves in the case where the right-hand side of the $\dot{c}=0$ curve is negatively sloped and hence the $\dot{c}=0$ curve is positively sloped. ${ }^{16}$ If $\mu=0$, the intersection point of the two curves is given by (23) and (24), which is $\mathrm{A}$ in the figure. Therefore, there is a unique saddle path that converges to A, which we refer to as the full-employment path. Along the path deflation gradually declines and eventually becomes zero.

If $\mu>0$, on the other hand, the steady state given by (21) does not exist within the range where $c+g \leq \theta$. This is illustrated in figure 2. Then, along the full-employment path, the economy reaches E, at which (23) and (24) are valid, within a finite time and thereafter stays there. As the figure shows, an increase in $\mu$ lowers $m$ but leaves $c$ unaffected in the new steady state. Therefore, if $\mu$ unexpectedly increases when the economy passes through B, it jumps up to D and thereafter follows DE. Eventually, it reaches $\mathrm{E}$, where the inflation rate is $\mu$ : an increase in $\mu$ is hence translated into an one-for-one increase in the inflation rate. If the monetary authority reduces the monetary expansion rate to zero in the new steady state so as to stabilize prices,

\footnotetext{
${ }^{16}$ When $g=0$, it is valid if $\eta \rho>\alpha$ and $\rho>\alpha$. Note that a positively sloped unique saddle path obtains even if the boundary curve is negatively sloped.
} 
private consumption stagnates in the short run, as the economy jumps down to $\mathrm{F}$ and moves along FA. The monetary authority thus faces the short-run tradeoff between inflation and consumption. It should gradually and intermittently decrease $\mu$ so as to avoid a sudden downward spike in private consumption.

The effect of an increase in the government purchases $g$ is illustrated in figure 3 . From (21), around the full-employment steady state where $c=\theta-g$, the dynamics of $m$ and $c$ are given by

$$
\frac{\dot{m}}{m}=\frac{\eta \theta \mu}{\theta-g+\theta \eta} \quad \text { and } \quad \frac{\dot{c}}{c}=\frac{\theta \mu}{\theta-g+\theta \eta}
$$

and hence on the equilibrium path $c$ and $m$ move so that they satisfy

$$
\left.\frac{m}{c} \frac{d c}{d m}\right|_{\text {path }}=\frac{\dot{c} / c}{\dot{m} / m}=\frac{1}{\eta} \text {. }
$$

From (23) and (24), on the other hand, the change in the steady state induced by an increase in $g$ must satisfy

$$
\left.\frac{m}{c} \frac{d c}{d m}\right|_{\text {steady state }}=\frac{\eta_{m}}{\eta} \quad \text { where } \quad \eta_{m}=-\frac{v^{\prime \prime}(m) m}{v^{\prime}(m)}(>0),
$$

where $\eta_{m}$ is the elasticity of money utility. By comparing (26) and (27), we find that an increase in $g$ shifts the steady state from $\mathrm{E}$ to $\mathrm{B}$ if $\eta_{m}<1$ and to $\mathrm{D}$ if $\eta_{m}>1$, as illustrated in figure 3. In either case, an increase in $g$ leads to a one-for-one decrease in $c$ in the long run (complete crowding out). In the short run, however, it may or may not stimulate private consumption, depending on the elasticity of money utility: $c$ increases if the elasticity is smaller than one and decreases if the elasticity is larger than one, since $\mathrm{B}$ and $\mathrm{D}$ are respectively located above and below the previous equilibrium path. If a fiscal expansion occurs at $\mathrm{A}$, the path jumps to either $\mathrm{F}$ or $\mathrm{H}$ and thereafter traces the new saddle path.

To sum up, along the full-employment path, any government interventions, either monetary or fiscal, affect aggregate demand in the short run, one way or the other. Since the economy eventually reaches full employment, however, any policies have only a transitory effect as market forces bring the economy back on track in the long run. We summarize our findings as follows. 
Proposition 3 If the marginal utility of liquidity has no positive lowerbound, i.e., $\lim _{m \rightarrow \infty} v^{\prime}(m)=0$, there is a unique equilibrium path that reaches the full-employment steady state. Along the full-employment path,

- a monetary expansion raises private consumption in the short run, while it does not affect private consumption in the long run,

- a fiscal expansion totally crowds out private consumption in the long run, while it may or may not increase private consumption in the short run.

\section{Persistent unemployment}

We have so far examined the case where the full-employment steady state, given by (23) and (24), exists and is eventually reached. Under certain conditions, however, our model also admits the possibility of persistent unemployment where the fullemployment steady state fails to exist. In this case, market forces alone are not sufficient to bring the economy back on track, and the government may have some role to play, even in the long run. It should be noted that the presence of persistent unemployment in this economy is not caused by real wage rigidity which tips the balance on the supply side of the market: although wages are sluggish due to fairness concerns, prices are fully flexible so that the real wage rate is always equal to the marginal productivity, i.e., $\theta=w(=W / P)$ from (9). It rather arises as a monetary phenomenon driven purely from the demand side.

\subsection{Cases for insatiable liquidity preferences}

The money demand curve is given by the relationship between $m$ and the liquidity premium $v^{\prime}(m) / u^{\prime}(c)$, which represents the nominal interest rate. It is negatively sloped since the liquidity premium decreases as $m$ increases. We now introduce a liquidity trap to this, which arises if $v^{\prime}(m)$ has a positive lowerbound:

$$
\lim _{m \rightarrow \infty} v^{\prime}(m)=\beta>0
$$


There is an indication that this property captures what Keynes envisioned as an essence of a monetary economy, i.e., an economy in which there is an asset whose marginal utility stays positive (Keynes, 1936, chap.17). ${ }^{17}$ As demonstrated in Ono (1994, 2001) and also in this model, this constant and perpetual craving for money can be a driving force for persistent demand shortages. Here, we offer two interpretations to justify this assumption.

Money as a secondary reward: One interpretation is to take the presence of the lowerbound literally as a formal representation of our perpetual craving for liquid assets, viz. money. Although the assumption of this kind is somewhat non-standard in modern macroeconomics, we argue that it is not as provocative as some may think: after all, there is no firm scientific ground to believe that the marginal utility of money should converge to zero either. To make a case for this interpretation, we focus on the nature of money as a reward as opposed to other rewards, called "primary rewards" in neuroscience, that are indispensable for the survival of the species. This distinction, which is clearly made in neuroscience, is potentially important in economics as well because that should have deep connection to the way we specify preferences for "secondary rewards" such as money, power and fame. ${ }^{18}$

The satiable nature of the demand for primary rewards such as food is intuitively clear. For instance, we all know from our experiences that if we eat enough, the marginal value of food eventually diminishes to zero and even negative. The assumption of the form $\lim _{c \rightarrow \infty} u^{\prime}(c)=0$, which is fairly conventional in economics, is presumably meant to capture this gut intuition. This does not necessarily mean, though, that we can apply this same logic to secondary rewards which derive their value from their associated primary rewards. The difference is clear at a superficial level: money is not something we directly consume but something we learn to appreciate though the asso-

\footnotetext{
${ }^{17}$ Using aggregate quarterly data in Japan and the Japanese survey data called NIKKEI RADAR, Ono, Ogawa and Yoshida (2004) empirically find this property to be well supported using both parametric and non-parametric methods.

${ }^{18}$ In neuroscience, Izuma et al. (2008) show that the brain areas activated by social rewards (acquisition of good reputation) overlap with those activated by monetary rewards.
} 
ciation between money and consumption. There is no convincing reason to believe that our gut intuition about our appetite, or any other more instinctive needs for primary rewards, should directly be applied to our craving for money as a secondary reward: at the very least, we never get tired of accumulating wealth in the same way as we get tired of eating food. In fact, evidence in neuroscience suggests that the diminishing nature of marginal utility, called "devaluation" in the field, for primary and secondary rewards is represented in different brain areas: the orbitofrontal cortex (limbic area) for primary rewards and the dorsal striatum (cognitive area) for secondary rewards. ${ }^{19}$ Although research along this line is still at its infant stage and there remains a lot to be seen, these findings seem to confirm a belief that the valuation of secondary rewards is related more to human cognition whereas that of primary rewards is related more to sheer instinct, indicating that simplistic analogy between primary and secondary rewards is not necessarily warranted.

Other-regarding preferences: An alternative interpretation, which is more widely accepted in economics, is to see this as a consequence of other-regarding preferences, such as the preference for "status" or the fear of lagging behind. ${ }^{20}$ Suppose, for instance, that agents are "status-seeking" in that they gain utility from the difference in wealth holdings. In this case, we can replace $v(m)$ by $v(m-\bar{m})$ where $\bar{m}$ denotes the social average of $m$. Since agents are all homogeneous and $m$ always equals $\bar{m}$ in the present setting, $v^{\prime}(m-\bar{m})$ stays to be fixed at $v^{\prime}(0)$ for any level of $m$. Our assumption (28) then follows if we let this value be $\beta$.

\footnotetext{
${ }^{19}$ Evidence, based on both animal studies (Ballein and Dickinson, 1998, 2000; Ballein and Ostlund, 2007) and human studies (Valentin et al., 2007), suggests that the orbitofrontal cortex is the region responsible for the devaluation of primary rewards. Research on the devaluation of secondary rewards is relatively scarce, but Pine et al. (2009) recently finds that the devaluation of secondary rewards is represented in the dorsal striatum. We thank S. Tanaka for enlightening us on the subject.

${ }^{20}$ See, for instance, Clark and Oswald (1998) for an extensive survey on the "status" literature.
} 


\subsection{Dynamics under insatiable liquidity preferences}

We now characterize equilibrium dynamics under (28). If the full-employment supply $\theta$ is sufficiently large and satisfies

$$
\frac{\beta}{u^{\prime}(\theta-g)}>\rho+\mu
$$

the liquidity premium exceeds the time preference for any $m$ whenever $c$ attains its full-employment level. This means that there exists no $m$ that can satisfy (24) and hence the full-employment steady state fails to exist. In this case, along the boundary curve of $c$ given in (25), $c$ gradually approaches $c^{u}$ defined by

$$
R^{u} \equiv \frac{\beta}{u^{\prime}\left(c^{u}\right)}=\rho+\alpha\left(\frac{c^{u}+g}{\theta}-1\right)
$$

If $\mu$ is sufficiently small, there exists an equilibrium path that leads to this stagnation steady state (the stagnation path, for short) which satisfies the transversality condition.

Proposition 4 Suppose that the marginal utility of liquidity has a positive lowerbound, i.e., $\lim _{m \rightarrow \infty} v^{\prime}(m)=\beta>0$. If (29) holds, the full-employment steady state does not exist. Moreover, if $\mu$ is small enough to satisfy

$$
\frac{\beta}{u^{\prime}\left(c^{u}\right)}>\mu,
$$

there arises a unique equilibrium path that leads to the stagnation steady state. Along the stagnation path, the steady-state consumption level converges to $c^{u}$ which falls short of the full-employment level $\theta-g$ and deflation occurs.

Proof: We can show that there exists a well-defined $c^{u}$ such that

$$
0<c^{u}<\theta-g
$$

To see this, define the difference of the two sides of (30) as

$$
\Phi(c) \equiv \frac{\beta}{u^{\prime}(c)}-\rho-\alpha\left(\frac{c+g}{\theta}-1\right)
$$


which is continuous in $c$. The intermediate-value theorem then guarantees the existence of a well-defined $c^{u}$ if

$$
\Phi(\theta-g)>0>\lim _{c \rightarrow 0} \Phi(c)=-\rho-\alpha\left(\frac{g}{\theta}-1\right) .
$$

The first inequality directly follows from (29) whereas the second inequality holds by assumption. This property also implies $\Phi^{\prime}(c)>0$ around the stagnation steady state (where $\Phi(c)=0)$ and hence

$$
\frac{\eta \beta \theta}{c^{u} u^{\prime}\left(c^{u}\right)}\left(=\frac{\eta R^{u} \theta}{c^{u}}\right)>\alpha
$$

Since $\Phi(c)$ is the inside value of the parenthesis of $\dot{c} / c$ in $(21)$ when the stagnation steady state is reached, the boundary curve of the $c$ dynamics is positively sloped with respect to $c$ around the stagnation steady state, as illustrated in figure 4. From (20) and (30) the steady-state inflation rate is then obtained as

$$
\pi^{u}=\alpha\left(\frac{c^{u}+g}{\theta}-1\right)<0
$$

From (21), (30) and (32), the transversality condition (13) is valid if and only if

$$
0>\frac{\dot{m}}{m}-\rho=\mu-\frac{\beta}{u^{\prime}\left(c^{u}\right)} .
$$

Evidently, this condition holds when $\mu$ is sufficiently small.

Q.E.D.

This situation is depicted in figure 4. In sum, on the equilibrium path, the economy never reaches the full-employment steady state. Along the stagnation path, the price level continuously falls, resulting in persistent deflation which makes the real balances $m$ keep expanding while satisfying the transversality condition. The consumption level falls short of the full-employment level $\theta-g$ and, due to this insufficient level of aggregate demand, unemployment persists in the steady state. Note that $c^{u}$ given by (30) is decreasing in $\alpha$, meaning that a recession becomes severer as the wage adjustment becomes less sluggish, since an improvement in the wage adjustment worsens deflation 
and makes holding money less costly. In the current setup, therefore, the role of nominal rigidity differs fundamentally from the conventional New Keynesian models where nominal rigidity is the direct cause of demand shortages. ${ }^{21}$

\subsection{Fiscal and monetary policies}

We are now in a position to draw policy implications in the stagnation phase with persistent unemployment. We start with the effect of a monetary expansion on aggregate demand. An important observation here is that $c^{u}$ is independent of $\mu$, so that a change in $\mu$ does not affect either the upper bound of $c$ or the steady-state inflation rate as long as $\mu$ satisfies (29) and (33). This fact leads to a serious implication regarding the effectiveness of monetary policies in the stagnation phase.

There are two cases we need to consider, but the implications are roughly the same. Suppose first that $c^{u}$ is not much smaller than the full-employment level $\theta-g$ such that

$$
\frac{\beta}{u^{\prime}(\theta-g)}-\rho<\frac{\beta}{u^{\prime}\left(c^{u}\right)}
$$

It then follows from (29) and (33) that

$$
\begin{gathered}
\mu<\frac{\beta}{u^{\prime}(\theta-g)}-\rho \Rightarrow \text { stagnation, } \\
\frac{\beta}{u^{\prime}(\theta-g)}-\rho<\mu<\frac{\beta}{u^{\prime}\left(c^{u}\right)} \Rightarrow \text { both stagnation and full employment, } \\
\frac{\beta}{u^{\prime}\left(c^{u}\right)}<\mu \Rightarrow \text { full employment. }
\end{gathered}
$$

Only the stagnation path exists when $\mu$ is relatively small (less than $\beta / u^{\prime}(\theta-g)-\rho$ ). Since $c^{u}$ is independent of $\mu$, this means that a small change in $\mu$ is totally ineffective when the economy is in this state. This situation is illustrated in figure 5. Once the monetary authority raises $\mu$ enough to violate (29) and hence enable $m$ to validate (24), the full-employment steady state, represented by $\mathrm{E}$ in figure 6 , is restored. Consequently, there emerges a new equilibrium path given by $\mathrm{BE}$ which leads to the

\footnotetext{
${ }^{21}$ As mentioned at the outset of this section, the real wage always equals the marginal productivity of labor $\theta$ due to perfect flexibility of commodity prices, so that there is no real rigidity in our model.
} 
full-employment steady state. Note, however, that the stagnation path AU also exists in this range. In the presence of multiple paths, there is no guarantee that the economy jumps to the new full-employment path, because it requires coordination among all agents. This means that the monetary authority needs an extra push, if it is to put an end to persistent stagnation. This can in fact be done by raising $\mu$ even higher, in which case only the full-employment path survives. A policy intervention of this kind apparently comes with a cost, however, as the economy necessarily suffers from high inflation. The classic dilemma between inflation and unemployment surfaces, now with a long-run implication: if it reduces $\mu$ in order to stabilize prices, the full-employment steady state disappears and the economy returns to the stagnation path AU which results in persistent unemployment.

On the other hand, if $c^{u}$ is much smaller than $\theta-g$ and

$$
\frac{\beta}{u^{\prime}(\theta-g)}-\rho>\frac{\beta}{u^{\prime}\left(c^{u}\right)},
$$

we find

$$
\begin{gathered}
\mu<\frac{\beta}{u^{\prime}\left(c^{u}\right)} \Rightarrow \text { stagnation, } \\
\frac{\beta}{u^{\prime}\left(c^{u}\right)}<\mu<\frac{\beta}{u^{\prime}(\theta-g)}-\rho \Rightarrow \text { no equilibrium path, } \\
\frac{\beta}{u^{\prime}(\theta-g)}-\rho<\mu \Rightarrow \text { full employment. }
\end{gathered}
$$

The situation is the same in the case above when $\mu$ is either relatively small (less than $\left.\beta / u^{\prime}\left(c^{u}\right)\right)$ or relatively large $\left(\beta / u^{\prime}(\theta-g)-\rho\right)$ : only the stagnation path exists in the former case while only the full-employment path exists in the latter. There is a difference in the case in-between: no equilibrium path exists in this intermediate range. Even in this case, though, we can draw the same conclusion: a modest increase in $\mu$ is totally ineffective and of no help to get the economy out of the stagnation phase.

We now turn to the effect of a fiscal expansion along the stagnation path which is also drastically different from that along the full-employment path. This is illustrated 
in figure 7 . Since (30) and (31) yield

$$
\frac{d c^{u}}{d g}=\frac{\alpha}{\left(\frac{\eta \beta \theta}{c^{u} u^{\prime}\left(c^{u}\right)}-\alpha\right)}>0,
$$

the equilibrium path shifts upward from $\mathrm{AF}$ to $\mathrm{DH}$ and thus $c$ rises in both the short run (from $\mathrm{B}$ to $\mathrm{D}$ ) and the long run (from $c^{u}$ to $c^{u \prime}$ ). If the government expands $g$ sufficiently to satisfy

$$
\rho>\frac{\beta}{u^{\prime}(\theta-g)},
$$

as in the case of $g_{2}$, the full-employment steady state, $\mathrm{K}$ in the figure, is eventually reached. It should be noted that if the government reduces $g$ to the previous level, the consumption $c$ returns to the previous level as well. In order to maintain a high level of consumption, the government must continuously hold $g$ at the same level.

Since market forces cannot be relied upon to restore full employment automatically, the role of the government is inherently different in the stagnation phase. Government interventions are not only effective, even in the long run, but also indispensable to realize full employment. We summarize our findings as follows.

Proposition 5 Along the stagnation path,

- a modest monetary expansion is totally ineffective and has no impact on neither private consumption nor the inflation rate,

- a substantial monetary expansion may restore full employment, although it necessarily entails high inflation,

- a fiscal expansion raises private consumption, in both the short run and the long run.

\section{Conclusion}

We incorporate various concepts of fairness to the fair wage model of Akerlof and Yellen (1990) and extend it to a dynamic general equilibrium model of a monetary economy as portrayed by Keynes (1936, chap.17). In this "Akerlof-Yellen meets Keynes" framework, we derive a version of the Phillips curve with its microeconomic foundation. 
We show that the inflation rate is governed by the liquidity premium, the subjective discount rate and the unemployment rate; around the steady state, in particular, it depends on the unemployment rate only, as in the original Phillips curve. More importantly, we also show that unemployment due to demand shortages may arise in the steady state. Effects of monetary and fiscal expansions are very different between under temporary unemployment and under persistent unemployment.

An increase in the monetary expansion rate raises short-run aggregate demand when the economy is on the full-employment path, although the steady-state aggregate demand is unaffected. If demand shortages occur under persistent stagnation, on the other hand, a modest increase in the monetary expansion rate is totally ineffective in stimulating aggregate demand. The monetary expansion rate must be significantly high to get the economy out of persistent stagnation. This obviously comes with a cost, however, since the economy inevitably suffers from high inflation once full employment is realized.

The effect of an increase in government purchases is also quite different between under temporary unemployment and under persistent stagnation. An increase in government purchases can either increase or decrease private consumption in the short run, depending on the elasticity of money utility, when the economy is on the fullemployment path: if the elasticity is higher (resp. lower) than one, it increases (resp. decreases) private consumption in the short run. Since the economy eventually restores full employment, though, an increase in government purchases totally crowds out private consumption in the long run. In contrast, under persistent stagnation, an increase in government purchases never fails to increase private consumption in both the short run and the long run. 


\section{Appendix: Stability under persistent stagnation}

This appendix shows the saddle-path stability of the dynamics. In the case where the full-employment steady state exists, there is a unique equilibrium path since the present model has essentially the same structure as the standard money-in-utility model. Thus, we focus on the stability when the economy is on the path that leads to the stagnation steady state.

For simplicity, we consider the case where $\mu=0$ and $g=0$. Since $m$ diverges to infinity, we consider $h(=1 / m)$ instead of $m$ and examine the stability of the two dynamic equations derived from (21):

$$
\begin{aligned}
\dot{h} & =\frac{c}{c+\theta \eta}\left(\frac{v^{\prime}(1 / h)}{u^{\prime}(c)}-\rho+\alpha \eta\left(1-\frac{\theta}{c}\right)\right) h, \\
\dot{c} & =\frac{\theta c}{c+\theta \eta}\left(\frac{v^{\prime}(1 / h)}{u^{\prime}(c)}-\rho-\alpha\left(\frac{c}{\theta}-1\right)\right),
\end{aligned}
$$

around the stagnation steady state where $c=c^{u}$ and $h=0$. The partial derivatives of the above two equations around the stagnation steady state are

$$
\begin{aligned}
\frac{\partial \dot{h}}{\partial h} & =\pi^{u}+\frac{c^{u} \eta_{m} R^{u}}{c^{u}+\theta \eta} \\
\frac{\partial \dot{h}}{\partial c} & =h \times d\left[\frac{c}{c+\theta \eta}\left(\frac{\beta}{u^{\prime}(c)}-\rho+\alpha \eta\left(1-\frac{\theta}{c}\right)\right)\right] / d c \\
\frac{\partial \dot{c}}{\partial c} & =\frac{\eta R^{u} \theta-\alpha c^{u}}{c^{u}+\theta \eta} \\
\frac{\partial \dot{c}}{\partial h} & =\frac{\theta c^{u} \eta_{m} R^{u}}{\left(c^{u}+\theta \eta\right) h} .
\end{aligned}
$$

Since $\eta_{m}=0$ because of the liquidity trap, from (31) and (32), we find

$$
\left(\frac{\partial \dot{h}}{\partial h}\right)\left(\frac{\partial \dot{c}}{\partial c}\right)-\left(\frac{\partial \dot{h}}{\partial c}\right)\left(\frac{\partial \dot{c}}{\partial h}\right)=\frac{\left(\eta R^{u} \theta-\alpha c^{u}\right) \pi^{u}}{c^{u}+\theta \eta}<0
$$

i.e., one of the characteristic roots is positive and the other is negative. Note that $c$ is jumpable whereas $h(=1 / m=P / M)$ is not since $W$ is not jumpable and $P=W / \theta$ from (9). We can thus conclude that the path is saddle-path stable. 


\section{References}

[1] Akerlof, G. A. (2007) "The New Case for Keynesianism", Challenge, Vol. 50, pp. $5-16$.

[2] Akerlof, G. A. and J. L. Yellen (1990) "The Fair-Wage Effort Hypothesis and Unemployment", Quarterly Journal of Economics, Vol. 105, pp. 255-284.

[3] Ariely D., G. Loewenstein and D. Prelec (2003) "“Coherent Arbitrariness": Stable Demand Curves without Stable Preferences", Quarterly Journal of Economics, Vol. 118, pp. 73-105.

[4] Balleine, B. W. and A. Dickinson (1998) "Goal-Directed Instrumental Action: Contingency and Incentive Learning and their Cortical Substrates", Neuropharmacology, Vol. 37, pp.407-19.

[5] Balleine, B. W. and A. Dickinson (2000) "The Effect of Lesions of the Insular Cortex on Instrumental Conditioning: Evidence for a Role in Incentive Memory", Journal of Neuroscience, Vol. 20, pp.8954-64.

[6] Balleine, B. W. and S. B. Ostlund (2007) "Still at the Choice-Point: Action Selection and Initiation in Instrumental Conditioning", Annals of the New Yokk Academy of Sciences, Vol. 1104, pp.147-71.

[7] Blanchard, O. J. and S. Fischer (1989) Lectures on Macroeconomics, Cambridge, Mass.: MIT Press.

[8] Clark, A. E. and A. J. Oswald (1998) "Comparison-Concave Utility and Following Behaviour in Social and Economic Setting", Journal of Public Economics, Vol. 70, pp.133-155.

[9] Dotsey, M., R. G. King and A. L. Wolman (1999) "State-Dependent Pricing and The General Equilibrium Dynamics of Money and Output", Quarterly Journal of Economics, Vol.114, pp.655-690. 
[10] Falk, A., E. Fehr and C. Zehnder (2006) "Fairness Perceptions and Reservation Wages - The Behavioral Effects of Minimum Wage Laws", Quarterly Journal of Economics, Vol. 121, pp. 1347-1381.

[11] Folger, R. and E.E. Kass (2000) "Social Comparison and Fairness: A CounterFactual Simulations Perspective", in J. Suls, L. Wheeler, eds, Handbook of Social Comparison: Theory and Research, New York: Plenum.

[12] Gali, J. (2008) Monetray Policy, Inflation, and Business Cycle: An Introduction to the New Keynesian Framework, Priceton: Princeton University Press.

[13] Gertler, M. and J. Leahy (2008) "A Phillips curve with an Ss foundation", Journal of Political Economy, Vol. 116, pp.533-572.

[14] Golosov, M. and R. E. Lucas Jr. (2007) "Menu Costs and Phillips Curves", Journal of Political Economy, Vol.115, pp.171-199.

[15] Hashimoto, K. (2004) "Intergenerational Transfer and Effective Demand", Economics Bulletin, Vol.5, pp.1-13.

[16] Izuma, K., D. N. Saito and N. Sadato (2008) "Processing of Social and Monetary Rewards in the Human Striatum", Neuron, Vol. 58, pp.284-294.

[17] Johdo, W. (2006) "Geographical Space and Effective Demand under Stagnation", Australian Economic Papers, Vol. 45, pp.286-298.

[18] Johdo, W., and K. Hashimoto (2008) "International Relocation, the Real Exchange Rate and Effective Demand", Japan and the World Economy, forthcoming.

[19] Kehoe, T. J. and E. C. Prescott (2007) Great Depressions of the Twentieth Century, Federal Reserve Bank of Minneapolis.

[20] Keynes, J. M. (1936) The General Theory of Employment, Interest and Money, London: Macmillan. 
[21] Krugman, P. (1998) "It's Baaack!! Japan's Slump and the Return of the Liquidity Trap", Brookings Papers on Economic Activity, No.2, pp.137-187.

[22] Lerner, M.J. (1980) The Belief in a Just World: A Fundamental Delusion, New York: Plenum.

[23] Mankiw, N. G. and R. Reis (2002) "Sticky Information versus Sticky Prices: a Proposal to Replace the New Keynesian Phillips Curve", Quarterly Journal of Economics, vol. 117, pp. 1295-1328.

[24] Matsuzaki, D. (2003) "The Effects of a Consumption Tax on Effective Demand under Stagnation", Japanese Economic Review, Vol. 54, pp.101-118.

[25] Murota, R. and Y. Ono (2008) "Growth, Stagnation and Status Preference", Osaka University, ISER Discussion Paper No. 715.

[26] Ono, Y. (1994) Money, Interest, and Stagnation, Oxford University Press.

[27] — (2001) “A Reinterpretation of Chapter 17 of Keynes's General Theory: Effective Demand Shortage Under Dynamic Optimization", International Economic Review, Vol.42, pp.207-236.

[28] (2006) "International Asymmetry in Business Activity and Appreciation of a Stagnant Country's Currency", Japanese Economic Review, Vol.57, pp.101-120.

[29] Ono, Y., K. Ogawa and A. Yoshida (2004) "Liquidity Trap and Persistent Unemployment with Dynamic Optimizing Agents: Empirical Evidence", Japanese Economic Review, Vol.55, pp.355-371.

[30] Pine, A., B. Seymour, J.R. Roiser, P. Bossaerts, K.J. Friston, H.V. Curran, and R.J. Dolan (2009) "Encoding of Marginal Utility across Time in the Human Brain", Journal of Neuroscience, Vol.29, pp.9575-81.

[31] Rodriguez-Arana, A. (2007) "Inflation and the Public Deficit when the Utility of Money is Insatiable", Japanese Economic Review, Vol. 58, pp.238-254. 
[32] Umphress, E.E., G. Labianca, D. Brass, E.E. Kass and L. Scholten (2003) "The Role of Instrumental and Expressive Social Ties in Employees' Perceptions of Organizational Justice", Organizational Science, Vol. 14, pp. 738-753.

[33] Valentin, V. V., A. Dickinson, and J. P. O'Doherty (2007) "Determining the Neural Substrates of Goal-Directed Learning in the Human Brain", Journal of Neuroscience, Vol. 27, pp.4019-26.

[34] Woodford, Michael (2003) Interest and Prices, Princeton UP.

[35] Yun, T. (1996) "Nominal Price Rigidity, Money Supply Endogeneity, and Business Cycles", Journal of Monetary Economics, Vol.37, pp.345-370. 


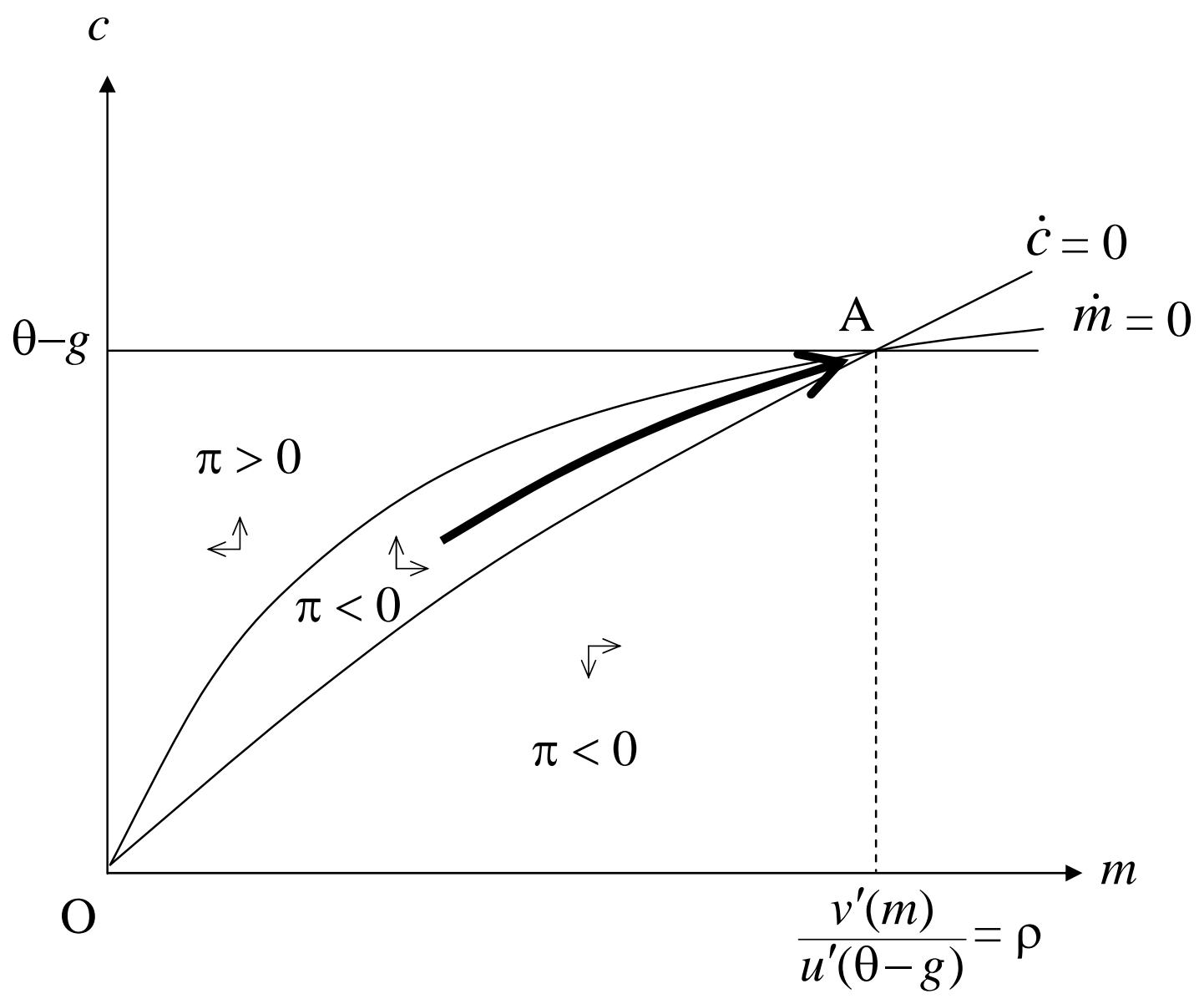

Figure 1: Full-employment Steady State 


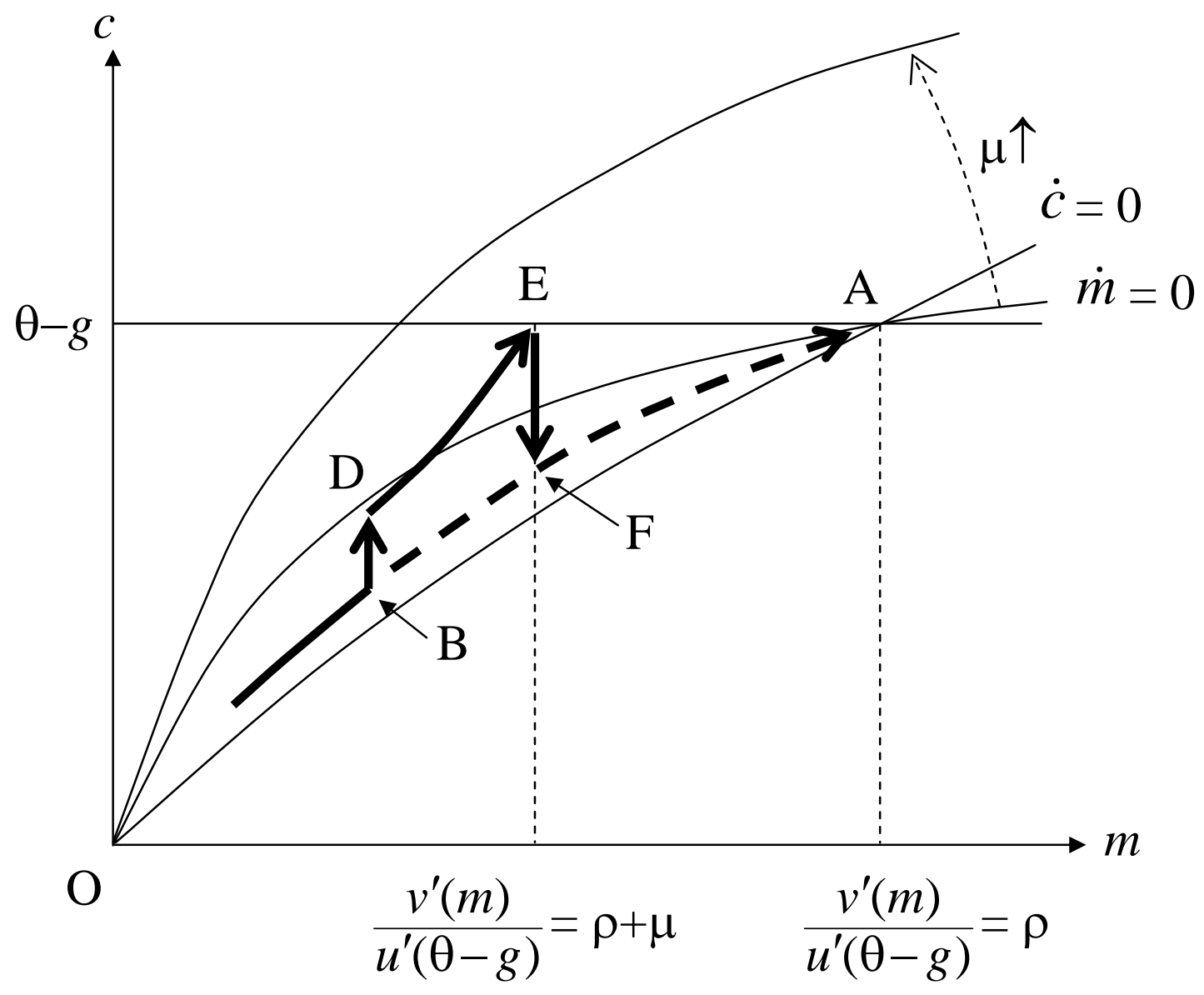

Figure 2: Monetary Expansion When Approaching Full Employment 


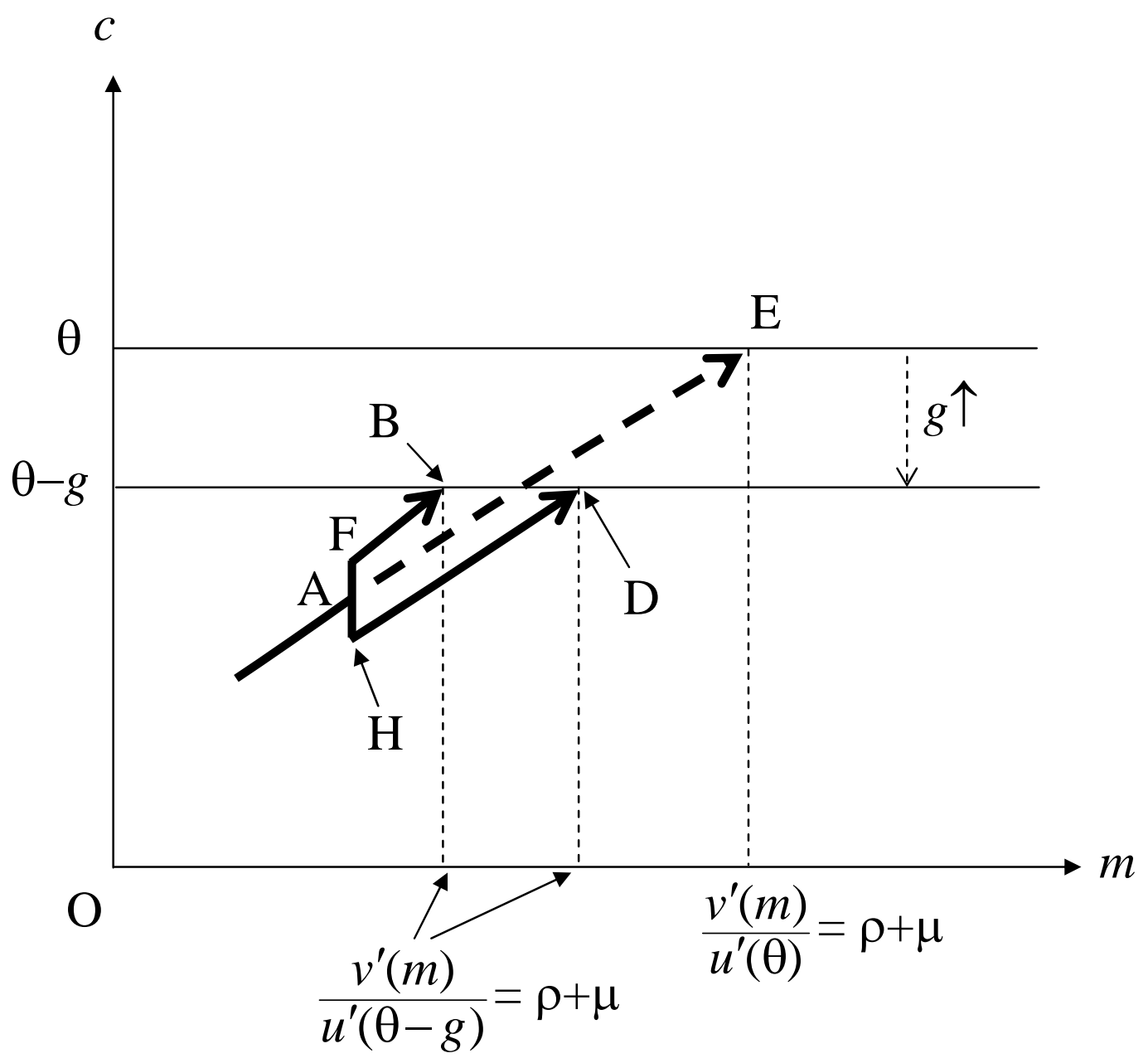

Figure 3: Fiscal Expansion When Approaching Full Employment 


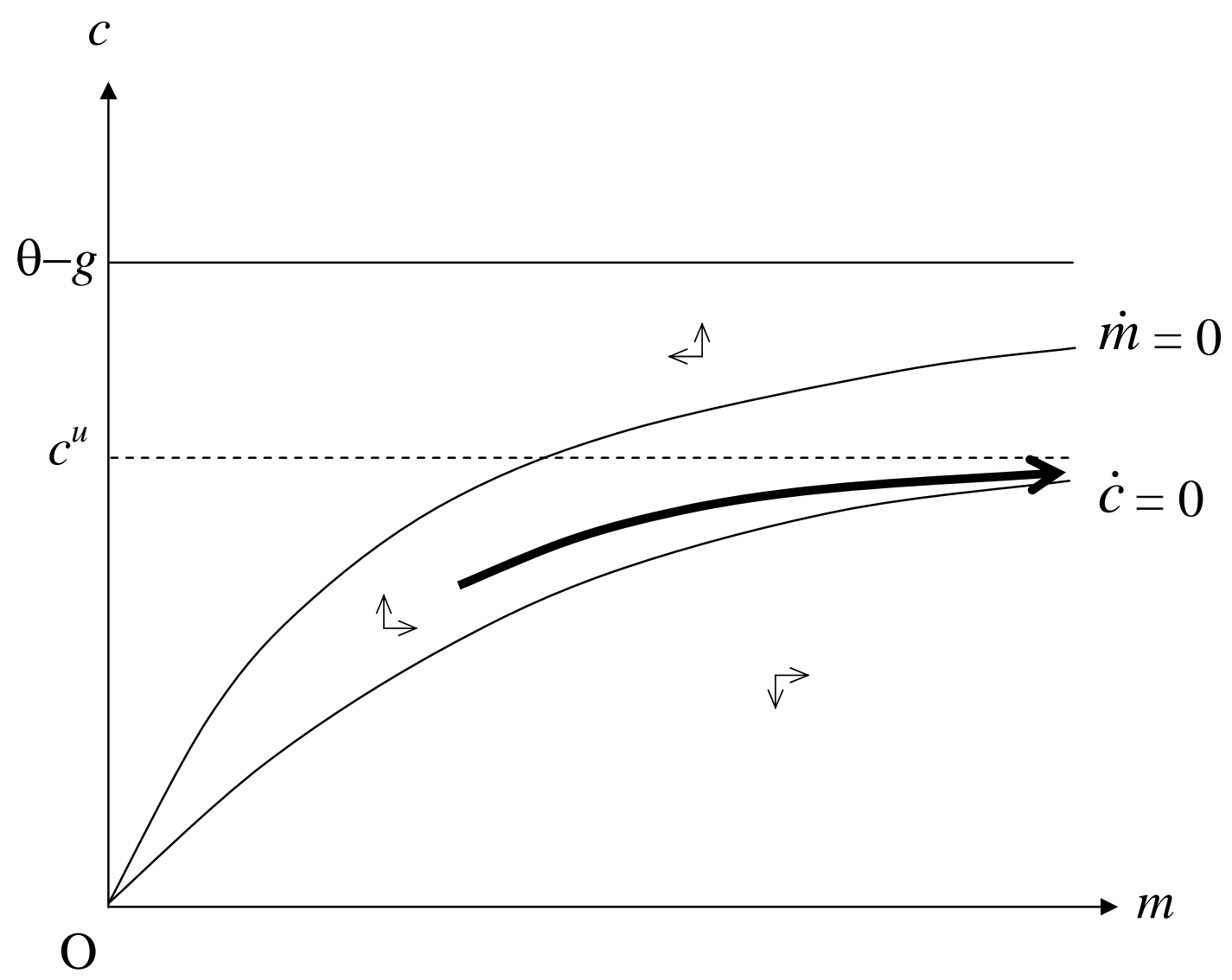

Figure 4: Stagnation Steady State 


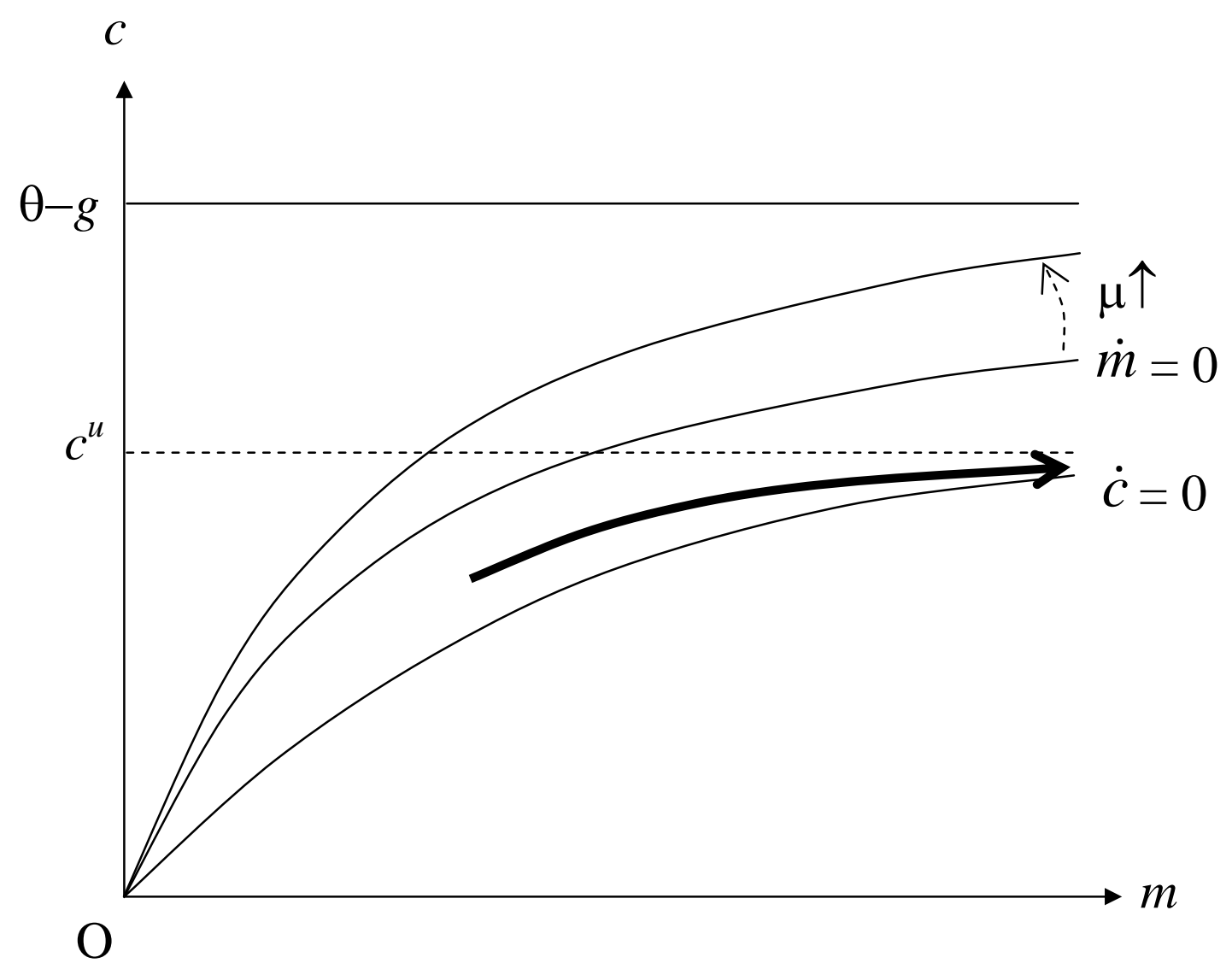

Figure 5: Monetary Expansion under Persistent Stagnation (when $\mu$ is small.) 


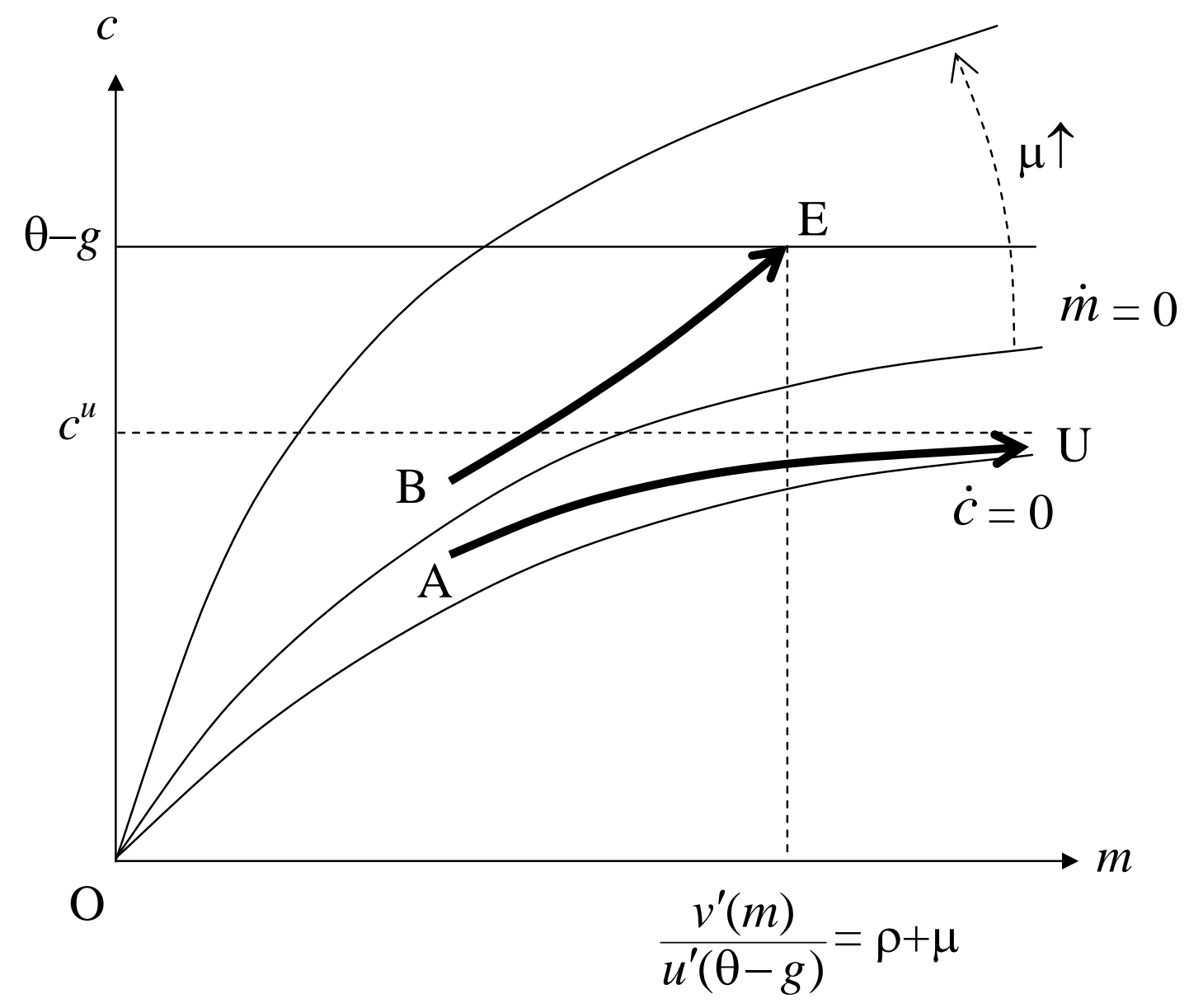

Figure 6: Monetary Expansion under Persistent Stagnation (when $\mu$ is large.) 


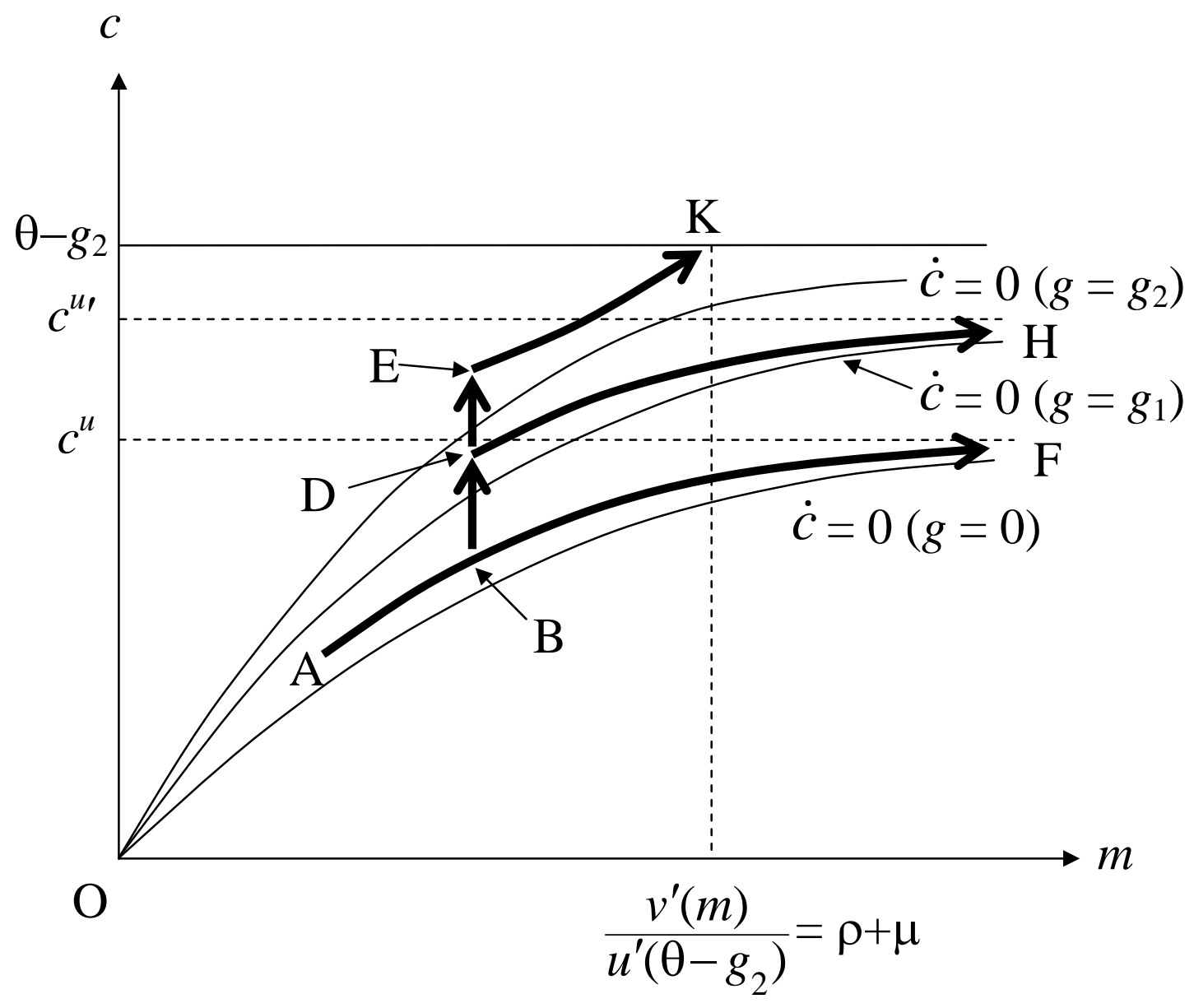

Figure 7: Fiscal Expansion under Persistent Stagnation 